\title{
Correction to: Genetic Enhancement of Crops for Tolerance to Abiotic Stress: Mechanisms and Approaches, Vol. I
}

Vijay Rani Rajpal, Deepmala Sehgal, Avinash Kumar and S. N. Raina

\section{Correction to:}

V. R. Rajpal et al. (eds.), Genetic Enhancement of Crops for Tolerance to Abiotic Stress: Mechanisms and Approaches, Vol. I, Sustainable Development and Biodiversity 20, https://doi.org/10.1007/978-3-319-91956-0

The original version of the book was inadvertently published with incomplete affiliation for volume editor "Vijay Rani Rajpal" in the frontmatter, which has been now updated. The erratum book has been updated with the change. 